\title{
The Use of Artificial Neural Network to Evaluate the Effects of Human and Physiographic Factors on Forest Stock Volume
}

\author{
${ }^{* 1}$ Yousefpoor M; Rostamie Shahraji, T; Eslam Bonyad, A; Salahi, M \\ 1Faculty of Natural Resources, Department of Forestry, University of Guilan, Somehsara, Guilan, Iran \\ ${ }^{2}$ Faculty of Basic Sciences. University of Guilan, Rasht, Iran \\ , *Corresponding author: ${ }^{1}$ Email address: tshahraji@yahoo.co.uk ${ }^{l}$ T. Rostamie Shahraji
}

\begin{abstract}
Increase in human factors coupled with physiographic factors will impact stock volume in forest ecosystems. The scale of this process and critical information in forestry management provide an incentive for the development of model to predict the forest stock volume. In this paper, we use data derived from Siahrood, Guilan Province, Iran using Field inventory by cluster sampling in a network $(1 \times 1 \mathrm{~km})$ with 90 clusters and 900 circular plots $\left(1000 \mathrm{~m}^{2}\right)$. To evaluate modeling approaches for stock volume responses to changing condition. The relationship between the standing volume and human factors and each physiographic factor were examined using Pearson and the Artificial Neural Network method. Based on Field observations it was observed that different stock volume exhibit in specific physiographic response to population density, livestock density, distance from village, aspect, slope and elevation. Results show that Multilayer Neural Networks with 12 nodes can predict the forest stock volume with the lowest RMSE $\left(48.76 \mathrm{~m}^{3}\right)$. In addition, the artificial neural network designed for the buffer of three populations with $85.5 \%$ accuracy was selected as the best model to predict the volume based on the mentioned components. The results suggest ANN is an effective approach to predict exact forest stock volume and human factors in certain topography conditions and provides useful information for the acceptable amount of standing inventory using the present human population in future experiment. (C) JASEM
\end{abstract}

http://dx.doi.org/10.4314/jasem.v20i4.14

Keywords: stock volume, human factors, physiographic factors, neural network 
Hyrcanian Forests are surviving from the Tertiary. In terms of geography, they are sub-order of EuropeanSiberian forest and are the continuation of European temperate forests, which start from northern Europe and continue to Caspian forests. Forest areas of Guilan province as parts of the northern forests are generally a Hyrcanian type and a wide range of habitat is covered by them. The rapid growth of human population in recent decades has increasingly threatened forests in the province. Low per capita income, lack of development, basic supplies and the most basic environmental culture has made local communities of forest dwellers to put pressure on natural resources in order to meet their needs (Rastaby et al., 2013). Although a large part of the northern forests including Guilan province is under the management of forestry plans, in many of these managed areas the pressures of human presence disrupts the structure, composition and generally the natural cycle of forests' ecological system. Over sixty thousands forest dweller families are living in forest areas of Guilan province, which are about 370,000 people who temporarily and permanently live there and their livelihood depends on the forest (mohammadi, 2008). Having a proper understanding of the interaction between humans and forests is considered essential in order to reach a successful conservation and management of forests (Bode, 2000), hence the influence of human populations living in forests is inevitable and requires techniques and methods that could measures the disruption caused by the presence due to provide the possibility of a systematic and careful planning to protect the forest (Shadytalab, 1998). Predicting standing volume as one of the most important quantitative features of forest stands' structure has a very considerable role in the planning and assessment of forest resources for managers and planners. Obviously, a lot of natural and unnatural factors are involved in the formation of forest stands; so that, physiographic factors are the most important natural factors (Mitusuda et al., 2007) and human factors are the most influential nonnatural factors. Three variables of slope, aspect and elevation are the most common indicators of physiographic factors that are commonly used in the measurement and mapping of vegetation cover (Liprieur et al., 1988) and can determine the microclimate in many cases (Giger et al., 1966). Based on studies in Hyrcanian Forests of
Azerbaijan, the tree density significantly changed due to distance between forest stands and population centers and accordingly the damage severity was defined (Sharnweber et al., 2007). Investigations in the tropical forests of Cambodia about the impact of human population density on the forests' structure and composition have been also conducted (Top et al., 2003, 2004, 2009). In addition, studies on population issues related to forests have been done in other parts of the world including India (Karanth et al., 2006), China (Wang et al., 2001) and Turkey (Sivrikaya et al., 2011). Generally, ecological and socio - economical aspects need special attention in sustainable forest management issues (Wolfslehner et $a l ., 2005)$. thus, studying how and to what extent the fact that forest resources are affected by demographic pressures is very important to determine the appropriate program for forest management. The aim of this research is to better understand the relationship between humans and forests using quantitative methods of human factors as well as the artificial neural networks to model these components.

This work presents a new approach for predicting the forest stock volume of Siahrood Roodbar hyrcanian Forest by using Multilayer Perceptron Neural Network. We propose a prediction of the forest stock volume by taking into account the measure of the variables (slope, aspect, elevation and human density). The predicted forest stock volume allows us to estimate these volumes by considering only four simple measures, the present method needs only $15 \%$ of the sample variables for the training stage making the field work easier and faster.

\section{MATERIALS AND METHODS}

The study area is a part of Siahrood Roodbar catchment in the south of Guilan province. The study area lies between $49^{\circ} 31^{\prime} 06^{\prime \prime}$ and $49^{\circ} 45^{\prime} 56^{\prime \prime} \mathrm{E}$ and $36^{\circ} 56^{\prime} 57^{\prime \prime}$ and $36^{\circ} 49^{\prime} 56^{\prime \prime} \mathrm{N}$ with an area of about 15,000 ha. The climate is a humid temperate with average annual rainfall of $903 \mathrm{~mm}$ and average annual temperature of $16.2{ }^{\circ} \mathrm{C}$. The dominant tree species in the area are beech with other species such as hornbeam, iron-tree, alder, maple, ash and 5000 people temporary and permanent reside there and are mainly engaged in ranching (Figure 1). 


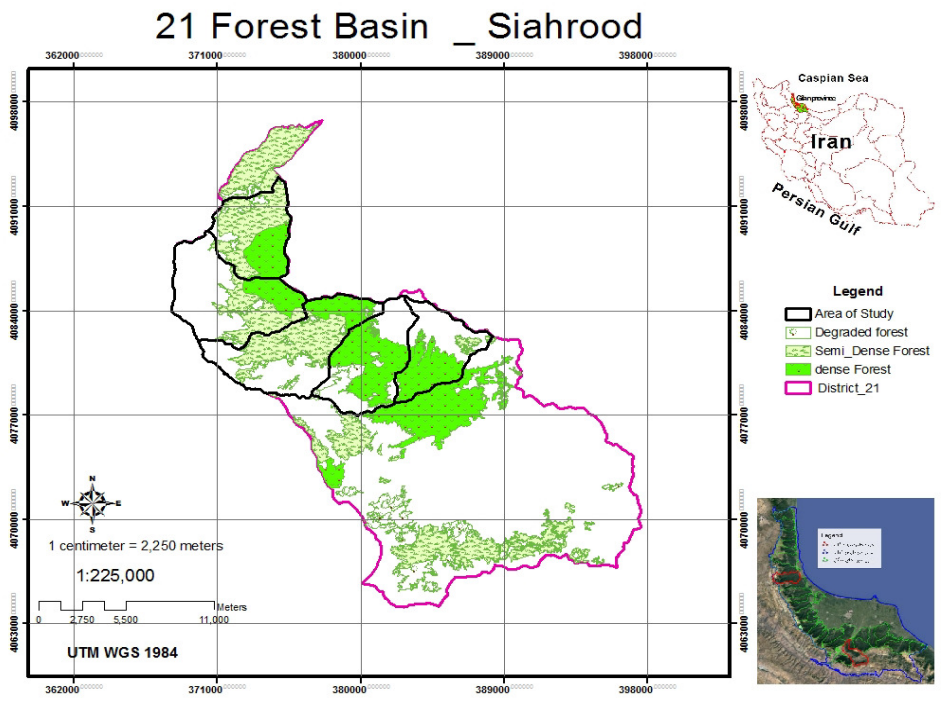

Fig. 1: Case study and land use type of Siahrood Roodbar forest, Guilan Province, Iran

Tree data: In order to measure the tree volume per ha, 90 clusters were systematic randomly determined in a network $(1 \times 1 \mathrm{~km})$ on the map and nature. Ten circular plots $\left(1000 \mathrm{~m}^{2}\right)$ in $150 \times 200 \mathrm{~m}$ intervals were placed in each cluster. In each of these plots, trees' data with a diameter more than $12.5 \mathrm{~cm}$ were recorded and the standing volume in the clusters were calculated using SPSS (Figure 2).

Demographic data: to determine population density around each cluster, seven circular layers were first defined at intervals of 1 to $7 \mathrm{~km}$ around each cluster using Arc GIS ver.9.3 and their position in each population buffer were determined by recording the coordinates of each village and house using Gps Map $60 \mathrm{cx}$ and the population of each layer was set by counting the number of houses and villages and were summarized and calculated in the form of buffer functions by the mentioned software (Top et al., 2006) (Figure 2).

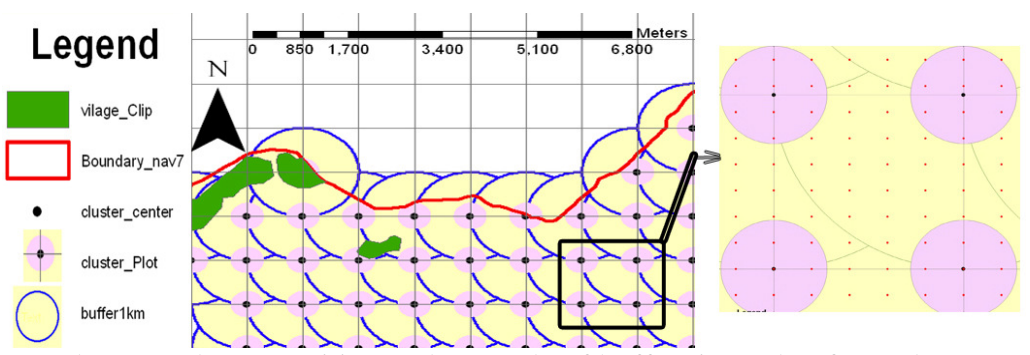

Fig. 2: Village and Forest cluster position and example of buffer rings $1 \mathrm{~km}$ from cluster

Topographic data: Maps of slope, aspect and elevation were prepared by DEM Shuttle Topography Radar Mission (STRM) data with a resolution of $30 \times$ $30 \mathrm{~m}$. Topography properties (slope, aspect and elevation) for each plot were then recorded by GPS with high precision and were extracted peer-to-peer from the raster map.

Tree volume calculation using volumetric equations: The volumes of all trees were calculated using the Smalian method, according to Eqs. (6) and (7), and the Tarif Table. The tariff table is a volumetric table that estimates tree volume from the $\mathrm{DBH}^{2}$. In order to verify the efficiency of the MLP network model proposed. These volumes are compared with volume obtained with 4 parameters (slope, aspect, altitude, population density) (Table 4).
2

The diameter at breast height 
For training the MLP, $20 \%$ of trees were randomly selected from each cluster to collect input and output sample sets. In the testing phase of the MLP, Slope, Aspect, elevation, and population density used to predict the tree volume. This phase is performed fro trees according to the prediction procedure described by Eq. (1). This procedure is described in Table 3.

Data analysis: After preparation and analysis of trees, human and physiographic data in clusters, in order to analyze data and detect the presence or absence of correlation between each of the independent variables (slope, aspect, elevation, population density, livestock density and distanse from village) and the dependent variable (standing volume), the Pearson correlation coefficient (r) was used (Top et al., 2006). This coefficient calculates the correlation between two variables and its value is between +1 and -1 . If the obtained value is positive, then changes in two variables occur in the same direction. Conversely, if the $r$ value is negative, then the two variables occur in opposite direction, which means that the value of a variable reduces with the increase in another variable and if the value is zero indicates that there is no relationship between the two variables (soltani et al., 2009).

Prediction methods and artificial neural networks Multilayer Perceptron (MLP) artificial neural network: A Multilayer Perceptron (MLP) neural network is composed of an input layer, one or more hidden layers and an output layer. The input signal propagates feed-forward through the network, layer after layer (Haykin, 1998). Fig.3. shows the MLP used in this work. Several activation functions may be used in the MLP (Haykin, 1998). The activation function used in this work for the hidden layer neurons for the output layer neurons was the hyperbolic tangent, also ;known as the tan-sigmoid or tansig, defined in Eq.(1).

$$
\varphi(a)=\tanh (a)=\frac{2}{(1+\exp (-2 a))}-1
$$

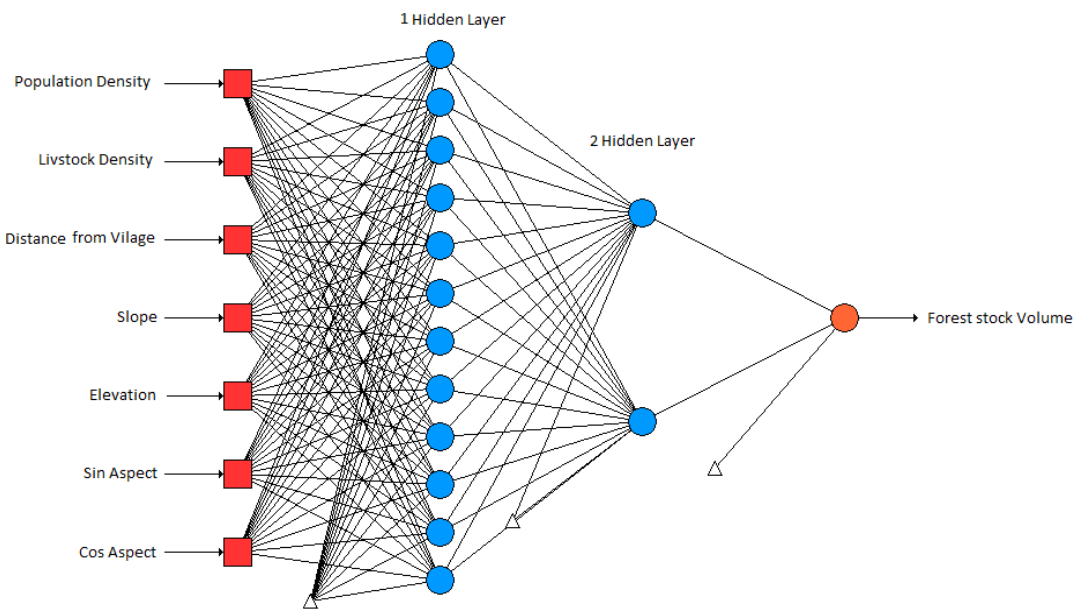

Fig.3: Three layer MLP architecture

Error calculation of predicted volumes by the MLP: In order to verify the accuracy of the volumes calculated from the independent variables (slope, aspect, elevation and human density) predicted by MLP, the following percentage errors were calculated: Root Mean Square (RMSE\%), Linear correlation (R) Özçelik et al., 2010), according to Eqs. (3),(4),(5), respectively. To calculate the percent of error was used the equation 2.

$\mathrm{E} \%=1 / \mathrm{N} \Sigma\left|\mathrm{V}_{\mathrm{pi}}-\mathrm{V}_{\mathrm{oi}} / \mathrm{V}_{\mathrm{oi}}\right| \times 100$

$\mathrm{N}$ : number of clusters

$\mathrm{V}_{\mathrm{pi}}$ : the predicted volume

$\mathrm{V}_{\mathrm{oi}}$ : the actual volume.

$$
\begin{aligned}
\text { RMSE } & =\sqrt{\frac{\sum_{i=1}^{n}\left(y_{i}^{a}-y_{i}^{e}\right)^{2}}{n}} \\
\operatorname{RMSE}_{\%} & =\left(\frac{\text { RMSE }}{\bar{y}^{a}}\right) 100
\end{aligned}
$$

$$
R=\frac{\sum_{i=1}^{n}\left[\left(y_{i}^{a}-\bar{y}^{a}\right)\left(y_{i}^{e}-\bar{y}^{e}\right)\right]}{\sqrt{\sum_{i=1}^{n}\left(y_{i}^{a}-\bar{y}^{a}\right)^{2}} \sqrt{\sum_{i=1}^{n}\left(y_{i}^{e}-\bar{y}^{e}\right)^{2}}}
$$

Where ya and ye are the vectors of actual stock volumes and estimated, respectively, ya and ye are the averages of the actual and estimated stock 
volumes values, respectively, and $\mathrm{n}$ is the number of stock volume measures.

\section{RESULTS AND DISCUSSION}

The MLP model proposed in this paper was based on the relationship between four parameters (population, livestock, distanse from village, slope, aspect and elevation) used as input, and the forest stock volume that is predicted as the output of the network. In order to verify the relationship between four parameters and Forest stock volume, the autocorrelation coefficient was calculated through the Pearson correlation coefficient (Eq.5).

Pearson correlation coefficients were calculated for each cluster. Table 2 and table 3 shows the correlation coefficients in 90 clusters. It can observe in Table 2 that there is a significant inverse correlation between standing volume and all of human factors in buffer 3 and this correlation increases from buffer 1 to buffer 3 . Also there is a significant positive relationship between elevation and standing volume. Whereas no significant relationship between slope and standing volume.

Table1. Descriptive statistics of Forest standing volume, Human population density, physiographic factors and Pearson correlation

\begin{tabular}{|c|c|c|c|c|c|c|c|}
\hline Properties of variation & $\begin{array}{l}\text { number of } \\
\text { clusters }\end{array}$ & Average & maximum & minimum & Variance & $\begin{array}{l}\text { Standard } \\
\text { devision }\end{array}$ & $\begin{array}{l}\text { Coefficient } \\
\text { of variation }\end{array}$ \\
\hline Volume $\left(\mathrm{m}^{3} / \mathrm{ha}\right)$ & 90 & 244 & 545 & 4 & 16384 & 128 & 53 \\
\hline Distance from Vilage $(\mathrm{m})$ & 90 & 1220 & 4402 & 0 & 894916 & 946 & 77 \\
\hline Buffer & B1 & B2 & B3 & B4 & B5 & B6 & B7 \\
\hline population & 144 & 668 & 1539 & 2784 & 4299 & 6115 & 8156 \\
\hline Livestock & 242 & 1202 & 2855 & 5279 & 8321 & 12078 & 16388 \\
\hline \multicolumn{5}{|c|}{ Descriptive statistics of physiographic factors } & mean & minimum & maximum \\
\hline \multicolumn{5}{|l|}{ Slope(\%) } & 44 & 11.5 & 79.5 \\
\hline \multicolumn{5}{|l|}{ Aspect $\left(^{\circ}\right)$} & 232 & 45 & 343 \\
\hline \multicolumn{5}{|l|}{ Elevation (m) } & 911 & 236 & 1937 \\
\hline
\end{tabular}

Table 2: pearson correlation coefficient between dependence and independence variable.

\begin{tabular}{|c|c|c|c|c|c|c|c|c|c|c|c|c|c|c|}
\hline & PB1 & PB2 & PB3 & PB4 & PB5 & PB6 & PB7 & LB1 & LB2 & LB3 & LB4 & LB5 & LB6 & LB7 \\
\hline VT & $0.61^{-}$ & $\begin{array}{c}- \\
0.7^{* *}\end{array}$ & $\begin{array}{c}- \\
0.73^{*} *\end{array}$ & $\begin{array}{c}- \\
0.64 * *\end{array}$ & $\begin{array}{c}- \\
0.6^{* *}\end{array}$ & $\begin{array}{c}- \\
0.4^{* *}\end{array}$ & $\begin{array}{c}- \\
0.34 * *\end{array}$ & $\begin{array}{c}- \\
0.57 * *\end{array}$ & $\overline{-}^{-}$ & $\begin{array}{c}- \\
0.71 * *\end{array}$ & $\begin{array}{c}- \\
0.62 * *\end{array}$ & $\begin{array}{c}- \\
0.53^{* *}\end{array}$ & $\begin{array}{c}- \\
0.36^{* *}\end{array}$ & $\begin{array}{c}- \\
0.21 *\end{array}$ \\
\hline
\end{tabular}

(VT:total volume. B1 to B7: population density in buffer 1 to 7. LB1 to LB7: Livestock density in buffer 1 to 7.

$$
* *: \mathrm{P}<0.01, *: \mathrm{P}<0.05)
$$

Table 3: pearson correlation coefficient between dependence and independence variable.

\begin{tabular}{|c|c|c|c|c|}
\hline & Elevation & Aspect & Slope & DV \\
\hline VT & $0.442 * *$ & $0.21 *$ & $0.16 \mathrm{~ns}$ & $0.69 * *$ \\
\hline
\end{tabular}

VT:total volume. DV: Distance from village

(EL:Elevation, B1 and B7:population density in buffer 1 to 7, VT:total volume,DV: Distance from village,LB1 to LB7: Livestock density in buffer 1 to 7. Ns: $\mathrm{p}>0.05, * *: \mathrm{P}<0.01, *: \mathrm{P}<0.05)$

-To determine the best model for predicting forest standing volume per hectare using human and physiographic components, the Artificial Neural Network Multilayer Perceptron (MLP) was used. The data were first standardized to increase the speed and accuracy of neural network processes based on the equation 1 .
$\mathrm{X}^{-}=\left(\mathrm{X}_{\mathrm{i}^{-}} \mathrm{X}_{\min }\right) / \mathrm{X}_{\max }-\mathrm{X}_{\min }$

$\mathrm{X}^{-}$: normalized data

$\mathrm{X}_{\mathrm{i}}$ : used data

$\mathrm{X}_{\min }$ and $\mathrm{X}_{\max }$ the lowest and highest data in each category

Standardized data were randomly divided into two parts, i.e. training and testing, for network training. Thus, $20 \%$ and $80 \%$ of data were used to test the model and for training data, respectively (Hilbert et al., 2001). To design a Neural Network, the 
independent variables of slope, aspect, elevation, population density, livestock density and distance from village were considered as the input layers and the dependent variable of volume per hectare of clusters was considered as output layer.
Forest standing volume prediction: Due to the large number of trees included in this study, Table 4 shows RMSE\% and Correlation \% (R) value produced by the testing phase of the forest standing volume prediction.

Table 4: Forest standing volume prediction-RMSE\% and Correlation

\begin{tabular}{|c|c|c|c|}
\hline Clusters & $\begin{array}{l}\text { Neuron } \\
\text { Number }\end{array}$ & RMSE $\left(\mathrm{m}^{3}\right)$ & Correlation (R) \\
\hline 90 & 12 & 48.76 & 0.85 \\
\hline
\end{tabular}

As shown in Table 4, RMSE is around $48.76 \mathrm{~m}^{3}$ which shows that the forest standing volume predicted by MLP are very close to the actual forest standing volume measured in the trees. This table also shows the correlation coefficient between predicted and measured forest standing volume. This coefficient is 0.85 that indicates there is a very strong linear correlation between the actual measured forest standing volume and the predicted by the MLP.
Fig. 4 a, shows with solid and dotted lines, respectively, the values of actual forest standing volume and the forest standing volume predicted by the 3 populations' buffer And Fig. $4 \mathrm{~b}$, illustrates the predicted and actual forest standing volume by the MLP. It can be observed in these figures that the values of the actual forest standing volumes and those predicted by the MLP are considerably coincident with each other.

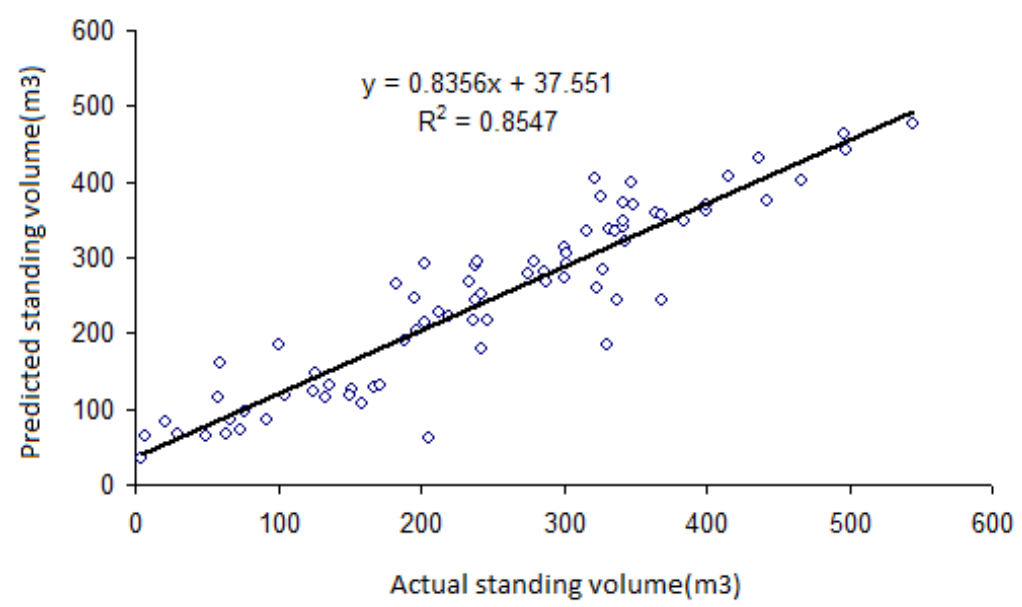

Fig 4a:- the correlation between actual and predicted values of standing volume in the 7 populations' buffer.

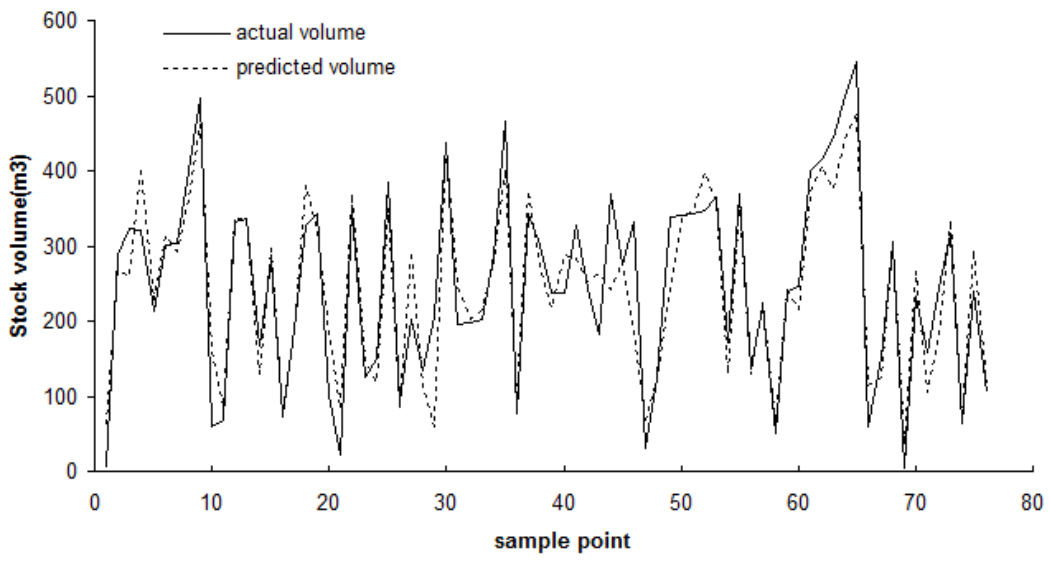

Fig 4b:- comparison between the actual and predicted Volume by the network 
Human population activities in natural ecosystems are considered as a highly influential factor (wang et al., 2001). The results of this study showed that there was a strong and significant inverse relationship between the standing volume and human factors in each of the population buffers and the correlation increased from buffer 1 to buffer 3 because of more villages in the higher buffer. Our results are consistent with the results of tropical forests of Cambodia (Top et al., 2004, 2006,2009), western forests of India (karanth et al., 2006) and Hyrcanian forests of Azerbaijan (schewnweber et al., 2007). In total, the correlations represented the quantitative influence of natural and unnatural factors. In this study, the performance of Multilayer Perceptron network (MLP) was also examined in order to predict the forest volume per hectares using some topographical and human factors. The results indicated that the aforementioned network with its own training algorithm has the ability to predict the volume per hectare. This technique can predict about $85 \%$ of forest standing volume by using topographical (slope, aspect, elevation) and human (population, Livestock and Distance from Vilage) factors. This confirmed the effectiveness of the human population and the effective role of physiographic factors on forest properties that is consistent with (Horsch, 2003; Guisan and Theurillat, 2000; Mitsuda et al., 2007). The use of artificial neural network (MLP) was evaluated in this study to increase the suitable predicting accuracy, which are corresponded to studies of (Hilbert and Ostendorf, 2001; Ingram et al., 2005) however, it is not consistent with Castellanos et al., (2007).

Conclusions: Todays, in most parts of the world, forest management planning is based on habitat and physiographic factors and issues related to human population as effective quantitative parameters receives less attention. Artificial neural network systems allow designers and planners to achieve interactions between them as well as realize parametric relations between them, which are essential for forest planning. It is recommended to use this technique for modeling more effective parameters in the form of function and variable so, the possibility of a greater initiative for forest managers and planners will be provided.

\section{REFERENCES}

Bode, W (2000). Waldende Vom Forsterwald zum naturwald .Beck:Die Deutsche Bibliothek. 199.

Castellanos, A; Blanco, AM; Palencia, V (2007). Application of Radial Basis Neural Network for area forest . International $J$ Information Theories and Applications. 14: 218 -222 .
Giger, R (1966). The climate near the Ground. Translated by Script from the 4th German ed., 2d print. Harvard University Press, Cambridge,MA, $611 \mathrm{p}$.

Guisan, A; Theurillat, J (2000). Equilibrium modelingof alpine plant distibution; how far can we go? Phytocoenologia 30:353-384.

Haykin, S (1998). Neural Networks- A Comprehensive Foundation, second ed. Prentice Hall, Upper Saddle River.

Hilbert, DW; Ostendorf, B (2001). The utility of artifical neural networks for modeling the distribution of vegetation in past, present and future climates Ecological modeling, 146(120:311-327.

Horsch, B (2003). Modeling the spatial distribution of mountain and sub alpine forests in the central Alps using digital elevation models. Ecological Modeling.168:267-282.

Ingram, JC; Dawson, TP; Whittaker, RJ (2005). Mapping tropical forest structure in southeastern Madagascar using remot sensing and artifical neural network. Remot Sensing of Environment, 94:491-507.

Ji, Y; Hao, J; Reyhani, N; Lendasse, A (2005). Direct and recursive prediction of time series using mutual information selection. In: IWANN 2005, Lecture Notes in Computer Science. Springer Verlag, p.1010-1017.

Karanth, k; Curran, ML; Reuning, D (2006). Village size and forest disturbance in Bhadra Wildlife Sanctuary, Western Ghats, India. Biological conservation. 1289(50):143-157.

Liprieur, VE; Durand, JM; Peyron, JL (1988). Influence of topography on forest reflectance using Landsat Thematic Mapper and digital terriandata. photogrammetry. Engineering Remot Sensing. 4(1):461-469.

Mitsuda,Y; Ito, S; Sakamoto, S (2007). Predicting the site index of Sugi plantations from GIS-derived environmental factors in Miyazaki Prefecture.$J$. Forest Research. 12(3):177-186.

Mohammadi, R (2008). Developing Document of Guilan natural resourses, Pooneh. P.63.

Rastaby, M; Jalilvand, H; Zandsyry, M (2013). Evaluation of socio-economic issues allotments Klgchy Zagros forests in this Province. Natural ecosystems Quartery. 3(2):59-70. 
Scharnweber, T; Rietschel, M; Manthey, M (2007). Degradation Stages of the Hyrcanian forests in Southern Azerbaijan. Archivfur Natuerschutz. und landschaftsforschung, 88(4): D-17487.

Shadytalab, J (1998). Social forestry. Research Project of Thehran University.

Sivrikaya, F; Cakir, G; Akay, AE (2011). Factors of Landuse/Cover change: A case study from Turkey. Scientific Research and Essays. 6(19): $3684-3696$.

Top, N; Mizoue, N; Ito, S; Kai, S (2003). Spatial analysis of woodfuel supply and demand in Kampong Thom Province, Cambodia. For Ecol Manage 194(11) 369-378.

Top, N; Mizoue, N; Kai, S (2004). Estimating forest biomass increment based on permanent sample plots in relation to woodfuel consumption: a case study in Kampong Thom Province, Cambodia. J For Res. 117(9): 1021-1044.
Top, N; Mizoue, N; Kai, S; Nakao, T (2006). Variation in woodfuel consumption patterns in response to forest availability in Kampong Thom Provivce, Cambodia. Biomass Bioenergy 27(3):57-68.

Top, N; Mizoue, N; Ito, S; Kai, S (2009). Effects of population density on forest structure and species richness and diversity of trees in kampong Thom Province,

Cambodia. Biodivers Concerv, 18(3): 717-738.

Wang, X; Feng, Z; Quyang, Z (2001). The impact of human disturbance on Vegetative carbon storage in forest ecosystems in china. Ecology

Management, 148(4): 117- 123.

Wolfslehner, B; Manfered, VH (2005). Application of the analytic network process in multi - criteria analysis of sustainable forest management. Journal of forest ecology and Management. 20(7) :157-170. 